\title{
PREVALENCE OF SCHISTOSOMIASIS AMONG PATIENTS ATTENDING QENA GENERAL HOSPITAL OVER THE YEARS 2011 AND 2012
}

By

\author{
FATMA GALAL SAYED ${ }^{1}$, MOHAMMED ALSALAHY MOHAMMED ${ }^{1}$, \\ MOHAMMED SAYED ABD-EL-KADER ${ }^{1}$, OSAMA HUSSEIN ABDALLA ${ }^{1}$ \\ and SAMAR S.AHMED ${ }^{2}$
}

Departments of Parasitology ${ }^{1}$ and Community Medicine ${ }^{2}$, Faculties of Medicine, Assuit University ${ }^{1}$ and South Valley University ${ }^{2}$, Egypt

\section{Abstract}

Schistosomiasis is a public health problem in Egypt. To detect the prevalence of schistosomiasis in Qena Governorate, 1601 urine and stool samples of patients attending Qena General Hospital were examined of whom 1601 patients had urinary symptoms and 893 patients had dysentery and bloody stool. Sheets were filled out on each patient. Also, a total of 7590 Bulinus truncatus and Biomphalaria alexandrina snails were collected from water bodies in Qena Governorate. The overall prevalence of $S$. haematobium was $13.9 \%$; with maximum among 6-18 year-old age group and higher in males than in females. Risk factors for S. haematobium infection were this age group; particularly males. However, males swim and play in water bodies and women wash cloths and utensils there, and children swimming or playing in canals. The S. haematobium peak of infection was in winter correlated with the highest prevalence in Dandara City, Qena City, AwladAmr and El Hijarat. S. mansoni were negative in the examined individuals. The infective rate among snails was $1.82 \%$ in B. truncatus and $0.0 \%$ among B. alexandrina and M. tuberculata.

Key words: Qena Governorate, Schistosomiasis, Snails intermediate hosts, Parasitologic examination.

\section{Introduction}

Human schistosomiasis--or bilharzia--is a parasitic disease caused by trematode flukes of the genus Schistosoma. By conservative estimates, at least 230 million people worldwide are infected with Schistosoma spp. Adult schistosome worms colonise human blood vessels for years, successfully evading the immune system while excreting hundreds to thousands of eggs daily, which must either leave the body in excreta or become trapped in nearby tissues. Trapped eggs induce a distinct immune-mediated granulomatous response that causes local and systemic pathological effects ranging from anaemia, growth stunting, impaired cognition, and decreased physical fitness, to organ-specific effects such as severe hepatosplenism, periportal fibrosis with portal hypertension, and urogenital inflammation and scarring (Colley et al, 2014). Schistosomiasis is the third most devastating tropical disease in the world, being a major source of morbidity and mortality for developing countries in Africa, South America, the Caribbean, the Middle East, and Asia (WHO, 2010).

In Egypt, both urinary and intestinal schistosomiasis coexists. Schistosoma haematobium was widely spread throughout the Nile valley while $S$. mansoni was confined to the Nile delta and extended somewhat to Upper Egypt (Hussein, et al, 2005).

An increase in the prevalence of schistosomiasis in Egypt, as a result of the Aswan High Dam, has for long time been predicted because of reclamation of land and conversion of annual flooding (basin irrigation) into perennial irrigation in Upper Egypt. Other reasons for the increase in schistosomiasis transmission due the ecological changes as a consequence of the High Dam were enhancing the transmission of the disease. In addition to the abundance of the snail intermediate host in the Nile, the absence of silt and decrease in water current velocity in the Nile Delta would have given higher chance for the miracidia to come in 
contact with the snails and for the cercariae to infect humans (Lotfy et al, 2011).

The study aimed to identify the prevalence and incidence of schistosomiasis among outpatients attended Qena General Hospital over two years, 2011 and 2012, and to examine the snails' infectivity of the main vectors; Bulinus truncatus and Biomphilaria alexandrina.

\section{Subjects, Materials and Methods}

This study was done on 1601 patients attending to Qena General Hospital from January 2011 to December 2012, all with history of water contact (irrigation or swimming or washing utensils), of whom 1601 were suspected to have urinary bilharziasis as indicated by terminal haematuria with or without dysuria. Sheets were filled out on each patient. Urine samples were examined directly or by Nucleopore techniques (Shaker et al, 1994).

Also, stool samples were collected from $893 / 1601$ patients suffering from dysentery and bloody stool and examined by direct smear and Kato Katz technique (AboMadyan et al, 2004).

A total of 7590 different snails were collected from the River Nile at Gena City and irrigation canals and identified as Bulinus truncatus, and Biomphilaria alexandrina according to Biocca (1980). B. truncatus snails were trapped from water bodies of different localities in Dandara, El-Tramsa, Gabalaw, and Awlad Amr.

Larval Trematode: Cercariae were recovered from the snails, which were placed in fresh water in Petri dishes. Non-shedding snails were kept in the laboratory and reexamined weekly to verify natural infectivity (Yousif et al, 1998). Then, all snails were dissected and the fleshy parts were microscopically examined. Snails shedding cercariae and those presenting infection by Mollusca larval stages were recorded. The recovered cercariae were classified (Yousif et al, 2013).

Statistical analysis: Data were computerized and analyzed using Statistical Package for Social Science (SPSS) version 16.1. The associations between categorical variables were tested by non-parametric tests as Chi square $\mathrm{X}^{2}$ test and level of significance was set at $p$ value less than 0.05 levels and 0.001 . Associations and comparisons were included if there were difference between infection by $S$. haematobium egg with sexes, age groups, residence and/or seasonal variation.

\section{Results}

The prevalence of positive $S$. haematobium was $1348 / 1601$ with a rate of $84.6 \%$. Details are given in tables $(1,2,3,4,5 \& 6)$ and figures $(1,2,3 \& 4)$.

Table 1: Prevalence of urinary schistosomiasis regarding sexes from January 2011 to December 2012

\begin{tabular}{|c|c|c|c|c|c|}
\hline \multirow{2}{*}{ Sex } & \multicolumn{2}{|c|}{ S. haemtobium negative } & \multicolumn{2}{|c|}{ S. haemtobium positive } & Chi-Square \\
\cline { 2 - 5 } & Frequency & Percent & Frequency & Percent & \\
\hline Male & 228 & 90.1 & 1168 & 86.6 & \multirow{2}{*}{$\mathrm{X}^{2}=885.997$} \\
Female & 25 & 9.9 & 180 & 13.4 & $\mathrm{DF}=1$ \\
Total & 253 & 100.0 & 1348 & 100.0 & $\mathrm{P}=0.000$ \\
\hline
\end{tabular}

Table 2: Prevalence of urinary schistosomiasis regarding age groups over two years

\begin{tabular}{|l|l|l|l|l|l|}
\hline Age group & \multicolumn{2}{|l|}{ S. haemtobium negative } & \multicolumn{2}{|l|}{ S. haemtobium positive } & $\begin{array}{l}\text { Chi- } \\
\text { Square }\end{array}$ \\
\hline$<5$ years & 2 & 0.8 & 27 & 2 & $\mathrm{X}^{2}$ \\
\hline 5 to $<18$ & 171 & 67.6 & 954 & 70.8 & $=1842.036$ \\
\cline { 1 - 5 } 18 to $<25$ & 49 & 19.4 & 251 & 18.6 & $\mathrm{DF}=3$ \\
\hline More than 25 & 31 & 12.3 & 116 & 8.6 & $\mathrm{P}=0.000$ \\
\hline Total & 253 & 100 & 1348 & 100 & \\
\hline
\end{tabular}


Table 3: Prevalence of urinary schistosomiasis regarding residence over two years

\begin{tabular}{|l|c|c|c|c|c|}
\hline \multirow{2}{*}{ Residence } & \multicolumn{2}{|c|}{ S. haemtobium negative } & \multicolumn{2}{|c|}{ S. haemtobium positive } & \multirow{2}{*}{ Chi-Square } \\
\cline { 2 - 5 } & No. & $\%$ & No. & $\%$ & \\
\hline Awlad-Amr & 71 & 28.1 & 226 & 19.7 & \multirow{2}{*}{$\mathrm{X}^{2}=2184.352$} \\
\hline Dandara & 79 & 31.2 & 355 & 26.3 & \multirow{2}{*}{$\mathrm{DF}=11$} \\
\hline Ganalaw & 2 & 0.8 & 38 & 2.8 & \\
\hline Ghawasa & - & - & 7 & 0.5 & \multirow{2}{*}{$\mathrm{P}=0.003$} \\
\hline Hijarat & 39 & 15.4 & 151 & 0.5 & \\
\hline Homidat & - & - & 10 & 0.7 & \\
\hline Karm Omran & - & - & 10 & 0.7 & \\
\hline Maana & 1 & 0.4 & 12 & 0.9 & \\
\hline Mahrosa & - & - & 16 & 1.2 & \\
\hline Qena City & 41 & 16.2 & 350 & 26.0 & \\
\hline El-Tramsa & 11 & 4.3 & 74 & 5.5 & \\
\hline Twairat & 9 & 3.6 & 59 & 4.4 & \\
\hline Total & 253 & 100.0 & 1348 & 100.0 & \\
\hline
\end{tabular}

Table 4: Prevalence of urinary schistosomiasis regarding seasonal variation over two years

\begin{tabular}{|c|c|c|c|c|c|}
\hline \multirow[t]{2}{*}{ Season } & \multicolumn{2}{|c|}{ S. haemtobium negative } & \multicolumn{2}{|c|}{ S. haemtobium positive } & \multirow[t]{2}{*}{ Chi-Square } \\
\hline & No. & $\%$ & No. & $\%$ & \\
\hline Winter & 80 & 31.6 & 415 & 30.8 & $\mathrm{X}^{2}=84.034$ \\
\hline Spring & 69 & 27.3 & 406 & 30.1 & $\mathrm{DF}=3$ \\
\hline Summer & 42 & 16.6 & 225 & 16.7 & $\mathrm{P}=0.007$ \\
\hline Autumn & 62 & 24.5 & 302 & 22.4 & \\
\hline Total & 253 & 100.0 & 1348 & 100.0 & \\
\hline
\end{tabular}

Table 5: Snails examined, number infected and percentage

\begin{tabular}{|c|c|c|c|}
\hline Type of snails & Snails examined & Snails infected & Infection \% \\
\hline Bulinus truncatus & 1700 & 32 & $1.88 \%$ \\
\hline Biomphalaria alexandrina & 5890 & 0 & $0 \%$ \\
\hline
\end{tabular}

Table 6: Number of Infected Bulinus truncatus according to their sizes

\begin{tabular}{|l|c|c|c|c|c|c|}
\hline \multirow{2}{*}{ Snail size } & \multicolumn{2}{|c|}{ Small sized } & \multicolumn{2}{c|}{ Medium sized } & \multicolumn{2}{c|}{ Large sized } \\
\cline { 2 - 7 } & Infected & Not & Infected & Not & Infected & Not \\
\hline Snail numbers & 890 & 19 & 570 & 11 & 240 & 2 \\
\hline
\end{tabular}

\section{Discussion}

Human infections with the parasites, especially schistosomes represent a significant segment of the global burden of illness. The schistosomes share the major biological and epidemiological features of macro-parasites (Chistulo et al, 2000). Schistosoma haematobium documented in Ancient Egyptian mummies as well as mummies from each of the ancient cultures of Peru, the American Southwest, and the Aleutian Islands (Clarke et al, 2014).

In the present study, $S$. haematobium was $13.9 \%$. Generally, in Qena Governorate the prevalence varied between $3.8 \%$ (Scott, 1937), to $4 \%$ (Wright, 1973), to $28.7 \%$ in three villages in Qus district (Mansour et al,
1981), up to an average of $37.1 \%$ (ranged from $23.9 \%$ to $64 \%$ ) in six rural villages of (King et al, 1982). Again, Khoby et al. (2000) in a Ministry of Health survey reported an incidence of $4.8 \%$ for urinary schistosomiasis, while Hammam et al. (2000) reported that the prevalence of $S$. haematobium infection among the villages ranged from 0 to $20.6 \%$ and in some villages prevalence excessed of $60 \%$.

In other Egyptian Governorates schistosomiasis haematobium showed different prevalence rates. It was $42 \%$ in Sohag (Wright, 1973), 27\% in Beni-Suef, 4\% in Aswan (Miller et al, 1981), 1\% in Beheira (Mickelson et al, 1993), 53.7\% in Giza (Talaat et al, 1999); 13.7\% in Al-Fayoum, 8.9\% 
in Al-Menia and 5.21\% in Assuit, $0.26 \%$ in Gharbiya, $0.45 \%$ in Kafr El Sheikha, 0.44\% in Al-Menoufia and 2\% in Dakhalia, 0.08 in Al-Qalubiya (El Khoby et al, 2000), and 2.8 $\%$ in Gharbyia (El-Hawey et al, 2000). These variations in prevalence may be attributed to human habitats, the changes in the irrigation system and to prevalence of the intermediate host prevalence due to epidemiological pictures.

In the present study, the prevalence of $S$. haematobium infection was higher in males than females, and this agreed with the study of Hammam et al. (2000) in Qena Governorate and El Khoby et al. (2000) in nine Egyptian governorates as they found that males had higher infection rates than females in all age groups and also similar phenomenon was reported in Giza Governorate (Talaat et al, 1999). No doubt, males due to the cultural and behavioral practices especially in Upper Egypt are associated more with working in farms, dealing with animals at the water ranks and canal swimming.

In the present study, age-stratified intensity of infection peaked at the 6 to 18 year old age groups followed by 19 to 25 years; which was explained by the more water contact for irrigation, swimming and washing utensils in females, with marked reduction below five years and above 25 years. The low rate of infection below five years may be explained by low frequency of water contact at this age by swimming or farming, and low infection rates above 25 years is explained by immunity.

The overall prevalence of infection in school children and early adolescence (6-18 years old) was $60.8 \%$ based on the examination of one urine sample. There is significant relationship between the prevalence of schistosomiasis and age $(\mathrm{P}=, 048)$, which agreed with the study done by Barakat et al. (1995), Nooman et al. (2000) Hammam et al. (2000), El Khoby et al. (1991; 2000), El Baz et al. (2003), Othman (2013) and Othman et al. (2014)
The highest rate of infection was mainly in 5 major sites belonging to Qena district which were Dandara, followed by Qena city, then Awlad Amr then Al Hijarat then Tramsa, and finally Twarat, but this not agree with result obtained by Abdel-Nasser and Bin-Dajem (2008), from their study Qena city and Tramsa had the highest rate of infection. This is because the present study done on other areas that not included in the previous study. There is significant relationship between the prevalence of schistosomiasis and residence in the current study $(\mathrm{P}=$, 0001).

In the present study, there was a significant association between intensity of infection and the seasonal variation as follows: the number of diagnosed infected cases was the highest during winter, then during autumn, followed by spring with the least degree of diagnosed infected persons during summer. This was attributed to the prepatent period of $S$. haematobium infection from time of exposure to the appearance of complains which agreed with data collected about snails in Qena Governorate by AbdelNasser and Bin-Dajem (2008) who found that the seasonal variation of the snails showed that the snail numbers peak in winter and autumn, and decrease in summer. There was monthly fluctuation of the number of diagnosed infected individuals as follows, December had the highest rate in diagnosis of infection followed by February then March then April then January, October, and November then May. Infection markedly decreased during June, July, August, September with the least number of infected individuals at August (which are the months of exposure in Egypt) and this explained by the time of infection until the time of occurrence of clinical manifestation of infection (formerly as the time needed for the life cycle to be completed in humans where the cercariae reach maturity and start laying eggs) which appear in urine mostly with the terminal haematuria. 
In the present study no cases with $S$. mansoni infection were diagnosed, which agreed with the results of Scott (1973) who did not find S. mansoni. Medhat et al. (1993) reported schistosomiasis mansoni in two villages in Assiut Governorate spreading from Lower to Middle and Upper Egypt. They concluded that $B$. alexandrina, which was present in some of the waterways for at least 15 years, were infected by local inhabitants returning from Iraq or by cattle traders or military recruits from the Nile Delta. Talaat et al. (1999) reported high prevalence of $S$. mansoni in a village in Giza and declared that an urgent need to include training programs for $S$. mansoni surveillance in the primary health care facilities of and to educate villagers to request examinations for $S$. mansoni as well as for $S$. haematobium infection. El Khoby et al. (2000) reported a prevalence of $0.44 \%$.

In the present study, 32 out of $1700 \mathrm{~B}$. truncatus (1.8\%) were shedding schistosome cercariae, Dandara and El-Tramsa. This is explain high intensity of infection in these 2 sites especially Dandara as it ranked the first district with higher infection rate of $S$. haematobium. King et al. (1982) found 9 out of 4,312 B. truncatus infected with schistosomes (0.21\%).Also, Abdel-Nasser and BinDajem (2008) in Qena Governorate reported $1.7 \%$ infected B. truncatus.

\section{Conclusion}

The present findings showed the situation of urinary schistosomiasis and snails intermediate hosts infectivity in some areas of Qena Governorate in Upper Egypt. The results obtained will be helpful in the development of simultaneous control of schistosomiasis snails and diagnosis of schistosomiasis infection at least in school aged children as well as to give information about this water-borne infectious disease and its risky complications.

\section{References}

Abdel-Nasser, AH, Bin-Dajem, SM, 2008: Prevalence of urinary schistosomiasis and infec- tions with trematode larval stages in Bulinus truncatus snails from Qena Upper Egypt. J. Appl. Sci. Res. 4, 11: 1610-7.

Abo-Madyan, AA, Morsy, TA, Motawea, SM, 2004: Efficacy of Myrrh in the treatment of schistosomiasis (haematobium and mansoni) in Ezbet El-Bakly, Tamyia Center, El-Fayoum Governorate, Egypt. J. Egypt. Soc. Parasitol. 34, 2:423-46

Barakat, R, Farghaly, A, El Masry, A, El Sayed, M, Hussein, M, Miller, F, 1995: Schistosoma mansoni in the Nile Delta, Egypt: a large scale epidemiological study in Kafr El Sheikh Governorate . Trop. Geograph. Med. 47:259-65.

Biocca, E, 1980: Mollusc vectors of schistosomiasis in Sardinia and in the Mediterranean area: taxonomy and epidemiology. Parassitologia 22, 3:247-55

Cheesbrough, M, 1998: District Laboratory Practice for Tropical Countries. Cambridge University Press, USA.

Chitsulo, L, Engels, D, Montresor, A, Savioli, L, 2000: The global status of schistosomiasis and its control. Acta Trop. 77:41-51.

Clarke, EM, Thompson, RC, Allam, AH, Wann, LS, Lombardi GP, et al, 2014: Is atherosclerosis fundamental to human aging? Lessons from ancient mummies. J. Cardiol. 63, 5:329-34

Colley, DG, Bustinduy, AL, Secor, WE, King, CH, 2014: Human schistosomiasis. Lancet. 383, 9936:2253-64.

El Baz, MA, Morsy, TA, El Bandary, MM, Motawea, SM, 2003: Clinical and parasitological studies on the efficacy of mirazid in treatment of schistosomiasis haematobium in Tatoon, Etsa Center, El Fayoum Governorate. J. Egypt. Soc. Parasitol. 33, 3:761-76.

El Hawy, A, Amer, M, Abdel-Rahman, A, Elibiary, S, Agina, M, et al, 2000: The epidemiology of schistosomiasis in Egypt: Gharbia Governorate, Egypt Am. J. Trop. Med. Hyg. 62, 2:S42-8.

El Khoby, T, Zemaity, O, Fenwick, A, 1991: Countries where both S. haematobium and $S$. mansoni are endemic: Progress in control of schistosomiasis since 1984 in Egypt. WHO, Geneva El-Khoby, T, Galal, N, Fenwick, A, Barakat, R, El-Hawey, A, et al, 2000: The epidemiology of schistosomiasis in Egypt: summary findings in nine governorates. Am. J. Trop. Med. Hyg. 62, 2:S88-99.

Hammam, H, Allam, F, Moftah, F, AbdelAty, M, Hany, A, et al, 2000: The Epidemiolo- 
gy of schistosomiasis in Egypt: assiut Governorate. Am. J. Trop. Med. Hyg. 62, 2:S73-9.

Hussein, MR, Abu-Dief, EE, El-Hady, HA, Mahmoud, SS, Salah, EM, 2005: Quantitative comparison of infected schistosomiasis mansoni and haematobium: animal model analysis of the granuloma cell population. J. Egypt. Soc. Parasitol. 35, 2:467-76.

King, CL, Miller, FD, Hussein, M, Barkat, R, Monto, AS, 1982: Prevalence and intensity of Schistosoma haematobium infection in six villages of Upper Egypt. Am. J. Trop. Med. Hyg. 31:320-7.

Lotfy, WM, Hanelt, B, Mkoji, GM, Loker, E S, 2011: Genotyping natural infections of Schistosoma mansoni in Biomphalaria alexandrina from Damietta, Egypt, with comparisons to natural snail infections from Kenya. J. Parasitol. 97, 1:156-9.

Mansour, NS, Higashi, GI, Schinski, VD, Murrell, KD, 1981: A longitudinal study of Schistosoma haematobium infection in Qena Governorate, Upper Egypt. I. Initial epidemiological findings. Am. J. Trop. Med. Hyg. 30: 795-805.

Medhat, A, Abdel-Aty, MA, Nafeh, M, Hammam, H, Abdel-Samia, A, 1993: Foci of Schistosoma mansoni in Assiut province in middle Egypt. Trans. Roy. Soc. Trop. Med. Hyg. 87, 4: 404-5.

Mickelson, M. Mickelson, F, Azziz, F, Gamil, A, Wahid, F, et al, 1993: Recent trends in the prevalence and distribution of schistosomiasis in the Nile Delta region. Am. J. Trop. Med. Hyg. 49, 1, 76-7

Miller, F, Hussein, M, Mancy, K, Hilber, M, Monto, A, et al, 1981: An epidemiological study of Schistosoma haematobium and S. mansoni in thirty-five Egyptian villages. Trop. Geograph. Med 33:355-65.

Nooman, Z, Hassan, A, Waheeb, Y, Mishriky, A, Ragheb, M, et al, 2000: The Epidemiology of schistosomiasis in Egypt: Ismailia Governorate. Am. J. Trop. Med. Hyg. 62, 2:S35-41.

Othman, AA, Bruschi, F, Ganna, AA, 2014: Helminth parasitic infections of the central nervous system: a diagnostic approach. J. Egypt. Soc. Parasitol. 44, 1:55-70

Othman, RA, 2013: Indirect haemagglutination test and ELISA as compared to Kato thick-smear in diagnosing Schistosoma mansoni. J. Egypt. Soc. Parasitol. 43, 3:841-8.

Scott, JT, 1937: The incidence and distribution of the human schistosomiasis in Egypt. Am. J. Hyg. 25:566-614.

Shaker, ZA, Hassan, SI, el-Attar, GM, Talaat, M, el-Nahal, HM, 1994: Use of Kato and $\mathrm{Nu}-$ cleopore techniques for qualitative diagnosis of schistosomiasis. J. Egypt. Soc. Parasitol. 24, 3: 656-62.

Talaat. M, El-Ayyat, A, Sayed, HA, Miller, F D, 1999: Emergence of Schistosoma mansoni infection in upper Egypt: the Giza governorate. Am. J. Trop. Med. Hyg. 60, 5:822-6

WHO, 2010: Schistosomiasis, Fact Sheet No 115; 2010. WHO, Geneva, Switzerland.

Wright, WH, 1973: Geographical distribution of schistosomes and their intermediate hosts. In: Epidemiology and Control of Schistosomiasis (Bilharziasis). Baltimore: University Park Press, USA.

Yousif, F, Ibrahim, A, el Bardicy, SN, 1998: Compatibility of Biomphalaria alexandrina, Biomphalaria glabrata and a hybrid of both to seven strains of Schistosoma mansoni from Egypt. J. Egypt. Soc. Parasitol. 28, 3:863-81

Yousif, F, Roushdy, M, El Dafrawy, S, 2013: Schistosoma mansoni cercarial host location and infection under simulated natural conditions in Egypt. J. Egypt. Soc. Parasitol. 43, 2:315-25.

Zaher, TZ, Abdul-Fattah M, Ibrahim, A, Salah H, El-Motyam, M, et al, 2011: Current status of schistosomiasis in Egypt: Parasitologic and endoscopic study in Sharkia Governorate. Afro-Egyptian J. Infect. End. Dis. 1, 1:9-11.

\section{Explanation of figures}

Figure1: Prevalence of urinary schistosomiasis regarding sexes over two years (2011 \& 2012).

Figure 2: Prevalence of urinary schistosomiasis regarding age groups over two years.

Figure 3: Prevalence of urinary schistosomiasis regarding residence over two years

Figure 4: Prevalence of urinary schistosomiasigarding seasonal variation over two years.

Figure 5: A- Bulinus truncatus, B- Biomphlaria alexandrina 

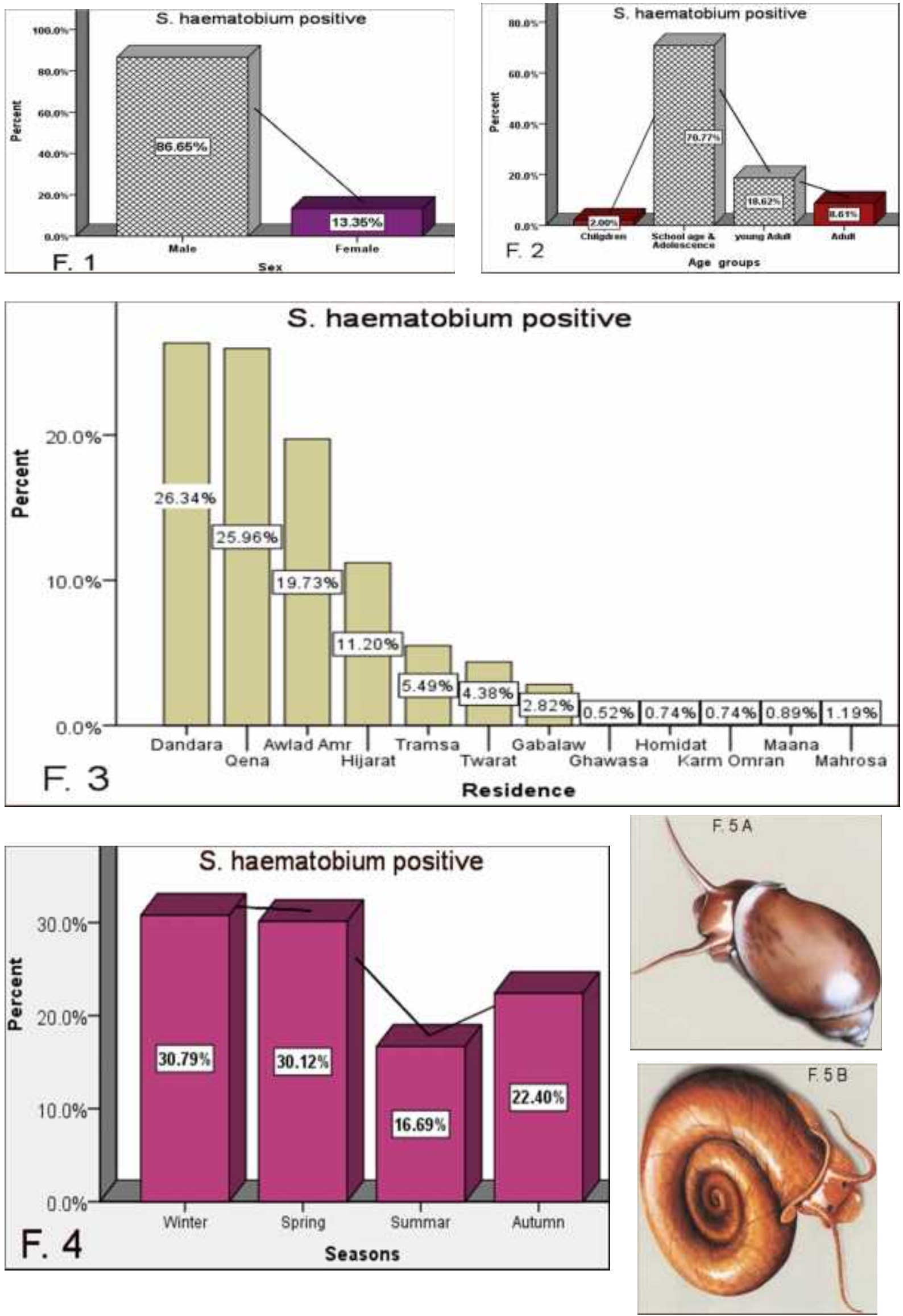